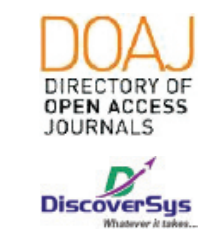

Published by DiscoverSys

\section{A large-liver abscess with severe anaemia in 6 years- old patient: A case report}

\author{
I Gusti Istri Agung Widnyani, ${ }^{1 *}$ I Putu Gede Karyana, ${ }^{1}$ \\ I Gusti Ngurah Sanjaya Putra, ${ }^{1}$ Nyoman Metriani Nesa ${ }^{1}$
}

CrossMark

\section{ABSTRACT}

Background: Liver abscess are infectious, space-occupying lesions in the liver; the two most common abscesses being pyogenic and amoebic. A pyogenic liver abscess (PLA) is a potentially lethal condition. This study aims to describe the signs, symptoms, and prognosis of pyogenic liver abscess in children with severe anaemia.

Case Description: Six years old boy complained about abdominal pain for 4 months before admitted to the hospital. The abdomen began to stiff 23 days before. Since 4 weeks, there was several episodes of fevers, more than 4 times but not more than 3 days, relieved by antipyretic. Every fever followed by a stomachache. His parents said he looked paler than before and his activities decreased, was sleepy and irritable. In physical examination, we found the patient looked anaemic, with a distended abdomen with hepatomegaly. Routine CBC revealed: WBC was 16.99 , Hemoglobin was $5.45 \mathrm{~g} / \mathrm{dL}$ platelet was 796.20, iron parameters was: iron serum: $11.27 \mathrm{ug} / \mathrm{dL}$ (normal: 50$120 \mathrm{ug} / \mathrm{dL}$ ) TIBC: $180 \mathrm{ug} / \mathrm{dL}$ (normal 225-450 ug/dL). A liver abscess $4.5 \mathrm{~cm} \times 5.1 \mathrm{~cm}$ with liquefaction was obtained by ultrasound and confirmed by abdomen MSCT with contrast 4,4 $\times 4,3 \times 6,1 \mathrm{~cm}$. The patient family refused abscess draining surgery, so only conservative therapy by antibiotics was given and further followed up in polyclinic. Nine-month after therapy, follow up by ultrasound was normal.

Conclusion: The sign and symptom of pyogenic LA were non-specific; abdomen MSCT confirmed the diagnosis with contrast. The prognosis was good.

Keywords: Liver abscess, pediatric, anaemia, conservative.

Cite this Article: Widnyani, I.G.I.A., Karyana, I.P.G., Putra, I.G.N.S., Nesa, N.M. 2020. A large-liver abscess with severe anaemia in 6 years-old patient: A case report. Intisari Sains Medis 11(1): 1-6. D0l: 10.15562/ism.v11i1.508

\section{INTRODUCTION}

The liver is an important and vital organ of the body. The liver is an organ located in the upper right part of the abdomen. The liver has two main lobes, both of which are made up of 8 segments. The segments are made up of a thousand small lobes. The lobules are connected to small ducts that connect with large ducts to ultimately from the common hepatic duct. This organ is subjected to numerous systemic infections viral, bacterial and parasitic and lies at the distal end of the portal circulation; it is therefore bathed with portal blood containing viruses, bacteria parasites, ova, products of digestion and other antigens. ${ }^{1,2}$

Hepatic or liver abscesses (LA) are infectious, 'Department of Child Health, Medical School, Udayana University/Sanglah General Hospital, Denpasar, Bali, Indonesia

${ }^{*}$ Correspondece to: I Gusti Istri Agung Widnyani; Department of Child Health, Medical School, Udayana University/Sanglah General Hospital, Denpasar, Bali, Indonesia; dr.agungwidnyani@gmail.com

Received: 2019-05-01 Accepted: 2020-01-03 Published: 2020-04-01 where 'Entamoeba histolytica' is endemic and is more prevalent in individuals with suppressed cell-mediated immunity. ${ }^{1}$

In both the types of liver abscesses, right lobe of the liver is the most likely site of infection. The clinical presentation of both the types may be exclusive with a combination of fever, right upper quadrant pain and hepatomegaly with or without jaundice..$^{1-4}$ The diagnosis for Pyogenic LA at laboratory investigations show an elevated white cell count, anaemia, hypoalbuminemia, elevated transaminase and alkaline phosphatase. Ultrasound (USG) is the imaging modality used for initial evaluation. The appearance of an abscess on USG initially is hyperechoic. Then after maturation and pus formation, it becomes hyperechoic with a distinct margin. USG has a sensitivity of $75 \%$ to $95 \%$. A computed tomography (CT) scan is more accurate than USG in the differential of PLA from other liver lesions. It is reported to have a sensitivity of approximately 95\%. In the other case with Amoebic LA, laboratory result may be raised bilirubin, leukocytosis, raised transaminase and alkaline phosphatase (non-specific). A fresh faecal sample may detect trophozoites containing erythrocytes. The serologic examination can be useful in the diagnosis of amoebiasis. USG 
typically reveals a round or oval hypoechoic area which is contiguous to the liver capsule, CT scan abdomen are sensitive studies for abscess. ${ }^{1-3}$

In both the types of liver abscesses, management consults of drug only, percutaneous drainage and drug or laparotomy and drug. In the case with Pyogenic LA, the antibiotic is broad-spectrum should be started to cover Gram-negative and Gram-positive aerobes and anaerobes. Initially, antibiotics should be administrated parenterally, and after 2 weeks, appropriate oral agents may be used 2-4 weeks. Medical therapy for Amoebic LA may be instituted using either a single agent or a combination of drugs for the extraluminal parasite. Metronidazole is effective in over $90 \%$ of cases. Therapy should be continued for at least 10 days. ${ }^{1,5}$

With modern treatment, the prognosis depends more on the underlying aetiology and co-morbid factors, although a delay in presentation and diagnosis contribute to a poor outcome. The risk factor most commonly associated with mortality include septic shock, clinical jaundice, coagulopathy, leukocytosis, hypoalbuminemia, multiple abscesses, intraperitoneal rupture, malignancy. Mortality is low with Amoebic LA compared Pyogenic LA. Abscesses is slow to resolve., ${ }^{5,6}$

In previous studies, abscess more than $6 \mathrm{~cm}$ in diameter should undergo drainage. Here we present a case of large LA with conservative therapy only and good improvement. Based on those mentioned above, the objective of this case report is to describe of pyogenic LA and to knows prognosis without drainage or surgical procedure.

\section{CASE REPORT}

A 6 years old boy was referred to the Pediatric Emergency Unit from a rural hospital. $\mathrm{He}$ complained about having pale skin and pain in his stomach. Stomachache was complained since 4 months ago, in the right upper quadrant of the abdomen, worsened when he in fever. After several episodes of aches, his right abdomen became stiffer dan pain was worsened if touched since 3 weeks before admitted. The tummy looked more prominent than usual.

The parents started aware that he was pale for 23 days before hospital admission. They noticed pale was worsened over days from his eyes, palm and skin. His activity decreased, but appetite was good. Since 4 weeks, there were several episodes of fever, occurred 4 times but not more than 3 days and relieved by antipyretic but a stomachache followed every fever.

The patient never had these symptoms before. He also never admitted to hospital previously. No family history of the same case and symptoms to the patient found. The history of chronic diseases in the family was also not found. History of immunization, delivery, nutrition, growth and development were normal, and there was no history of surgery and transfusion.

According to physical examination, we found the patient was in a weak condition and looked pale. Blood pressure was $100 / 70 \mathrm{mmHg}$, body temperature was $37.2 \mathrm{C}$, pulse rate was 120 beats per minutes regularly, respiratory rate was 32 times per minutes, and $\mathrm{O} 2$ saturation was $97 \%$. He had pale conjunctiva, buccal mucous and tongue. No lymph enlargement was found. The abdomen was distended, pain on palpation of liver, enlargement of liver palpable $7 \mathrm{~cm}$ below the right costal arch, smooth surface, sharp edge.

Laboratory results were leucocytosis $(16.99 \times$ 103/uL) shift to left, differential count (Neutrophils 71.52\%: Lymphocytes 19.89\%), anaemia with hypochromic microcytic red blood cells $(5.45 \mathrm{~g} /$ dL HB, MCV: $61.84 \mathrm{fL}, \mathrm{MCH}: 17.48 \mathrm{pg}$ ) and thrombocytosis $(796.20 \times 103 / \mathrm{uL})$ it was confirmed by peripheral blood smear. Blood iron profile was low (low iron serum, low TIBC, high rate of ferritin). Elevated CRP $(181.17 \mathrm{mg} / \mathrm{dL},<5.00 \mathrm{mg} / \mathrm{dL}$ normal range). Liver function revealed high on gamma GT and globulin, and other markers were in the normal range. The urine and faecal analysis were also normal.

Abdominal ultrasound revealed an abscess in liver size $4.5 \times 5.1 \mathrm{~cm}$ and CT scan with contrast examination had the same conclusion, with an abscess in liver size in $4.4 \times 4.3 \times 6.1 \mathrm{~cm}$ in the right lobe (Figure 1 and 2). We assessed the patient with Liver Abscess with Severe Anaemia.

The patient treated for anaemia along with treatment for liver abscess. Packed Red blood cell (PRC) was given. Average of 2 combinations treated liver abscess of antibiotics. Ceftriaxone $100 \mathrm{mg} / \mathrm{Kg} /$ day IV in two divided doses and Metronidazole $15 \mathrm{mg} / \mathrm{Kg}$ IV loading dose (once) continued to $7.5 \mathrm{mg} / \mathrm{Kg} /$ dose 3 times in a day. Antibiotics were given for 10 days. Pediatric surgery consultation was obtained, but parents refused any interventional surgery therapy. The clinical presentation gets a better appearance, no fever, decreased right abdominal pain, but still stiff in palpation, negative serology amoeba, a blood culture showed no growth and progressive improvement in laboratories. The patient was discharged from hospital and treatment continued with cefixime oral $5 \mathrm{mg} / \mathrm{kg} /$ dose 2 times in a day for 2 weeks. After 2 weeks, the patient came to the clinic and there were no abdominal pain and fever found. In addition, the physical examination revealed reduced bulging in the right abdomen and no pain on palpation. Laboratory result showed slight transaminitis but 


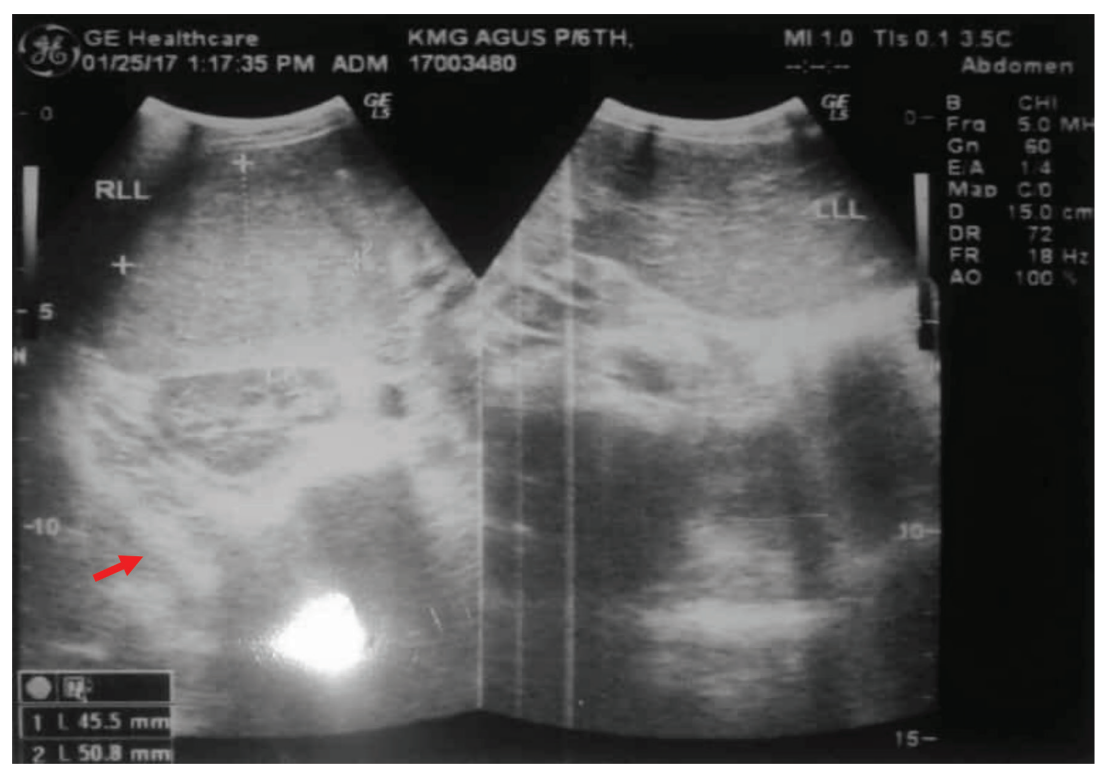

Figure 1 The abdominal ultrasound showed an abscess in the liver

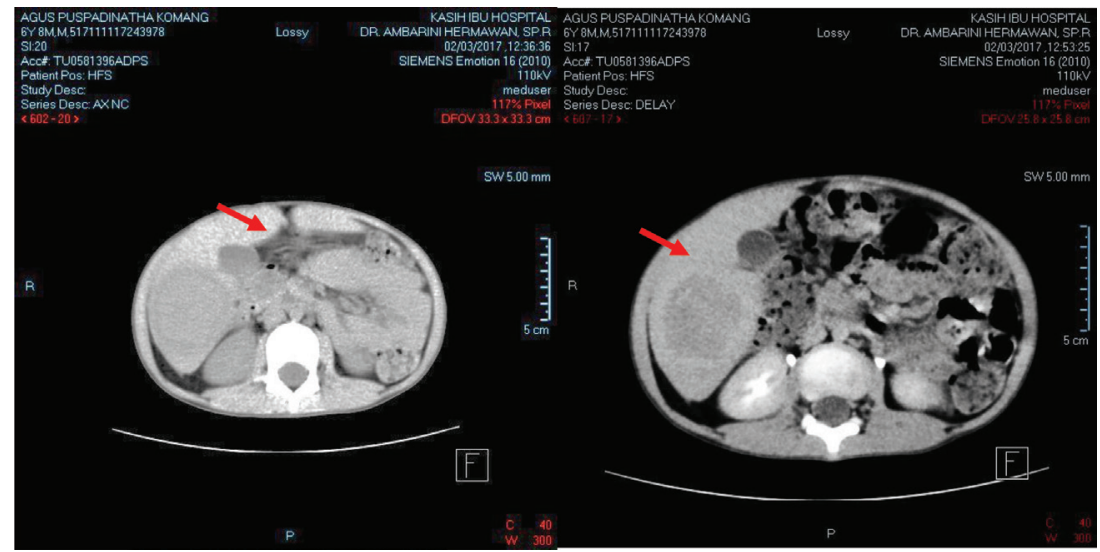

Figure 2 CT scan with contrast examination showed an abscess in the liver
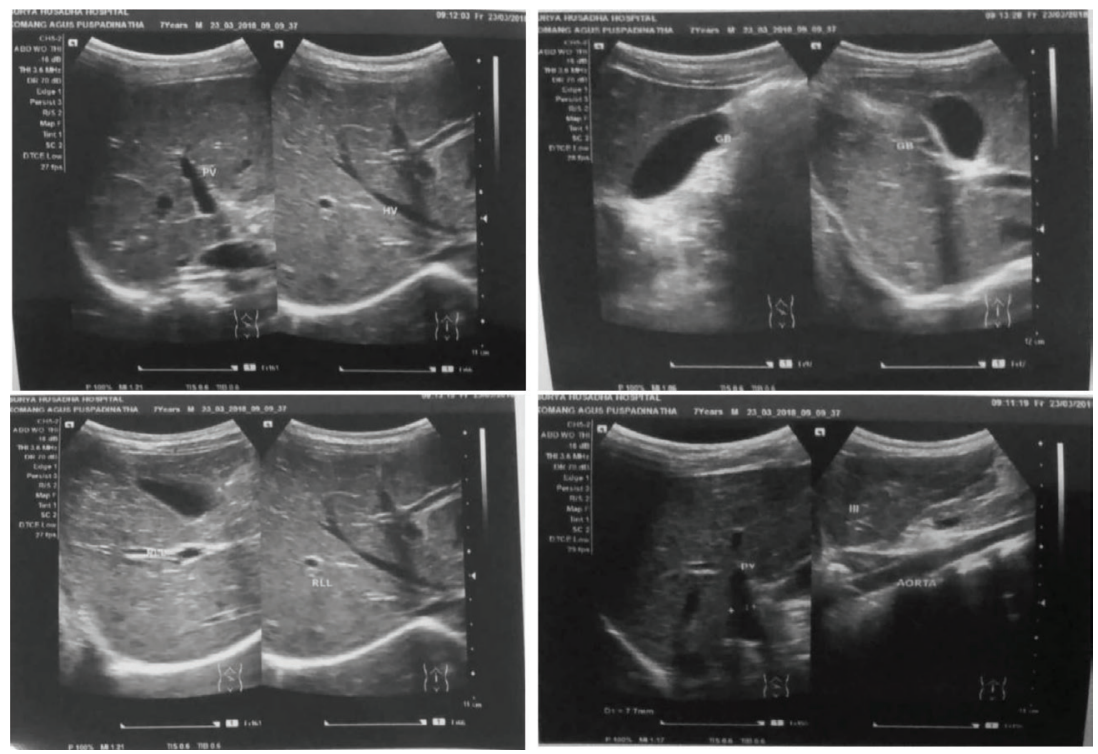

Figure 3 Abdominal ultrasound 9 months after treatments showed liver was normal a normal septic marker. Besides, the abdominal ultrasound 9 months after treatments showed liver was also normal (Figure 3).

\section{DISCUSSION}

A liver abscess (LA) is a frequently encountered disease in children from developing countries, especially those living in the tropical and subtropical zones. It has become relatively uncommon in developed countries. ${ }^{7}$ LA is seen often in children with a significant debilitating disease, granulocyte dysfunction, sickle cell disease, and congenital or acquired immunosuppression. The biliary tract is an important source of pyogenic LA. Congenital anomalies, biliary strictures and other anatomic abnormalities lead to obstruction of bile flow, resulting in bacterial proliferation. When the biliary tract is the source of LA, there are multiple abscesses. $^{2,8}$

Predisposing causes of liver abscesses in children there are (1) parasitic Infestations: parasitic infestations are thought to predispose to pyogenic liver abscesses in children. Almost all parasites including ascariasis, schistosomiasis, fascioliasis, Trichuris trichiura, necator, and ancylostoma infestation have been reported as an association. Tissues from liver biopsies or surgical and autopsy specimens in patients with liver abscesses have documented eggs, larvae, and antigens of parasites. Laboratory clue to an underlying parasitosis is often peripheral eosinophilia, hyper IgE levels, antibodies to various parasites and detection of eggs and larvae in the stool. (2) Chronic Granulomatous Disease (CGD) is a rare inherited primary immunodeficiency where phagocytes cannot destroy catalase-positive bacteria and Fungi. ${ }^{3}$ Defect in phagocytic cells respiratory bursts lead to life-threatening infections, including liver abscesses. (3) Skin infections: these provide a source of bacteremia and inoculation of disease in the liver. (4) Protein calorie malnutrition: there is the likelihood of correlation with liver abscesses and malnutrition in children. (5) Post-trauma; trauma predisposes to liver abscesses both by direct injury to the liver or by providing habitat for the proliferation of organisms elsewhere. ${ }^{3}$

Bacteria and other organism can enter the liver through various routes including the biliary tract, portal vein, and hepatic artery. Infections in organs in the portal bed can also result in localized septic thrombophlebitis, releasing septic emboli into the portal circulation which are trapped by hepatic sinusoids and become the nidus for hepatic abscess formation. Approximately two thirds of LA occur in the right lobe of the liver and the majorities are solitary. The predilection for the right hepatic lobe 
can be attributed to the volume of the right portal vein flow and to that common portal vein continues the direction of the common portal vein while the left portal vein takes a more horizontal direction. ${ }^{3}$

The most common cause of LA are pyogenic (negative or positive gram bacteria) and amoebic, about $80 \%$ of the case are pyogenic and only $10 \%$ amoebic. ${ }^{9}$ Worldwide, the most common pathogen isolated from LA in children is Staphylococcus aureus both in developed and developing countries. E. Coli, Klebsiella and Enterobacter are the other species focused in LA. Many of reports on amebic LA in children 1\%-7\% of the population is infected with Entamoeba histolytica and less than $1 \%$ of the infected have extraintestinal disease. ${ }^{3}$

From the various case of LA, fever and abdominal pain are the most usually clinical finding. Clinical presentation of pyogenic LA is non-specific and similar to that of that other hepatobiliary inflammatory or infectious process. A combination of nonspecific systemic symptoms is the most common presentation: including fever and rigours, nausea and vomiting, right upper quadrant pain, anorexia, weight loss, weakness and malaise. Common laboratory finds leukocytosis and mild anaemia. ${ }^{5,10}$ In our case study, the clinical appearance similar to other study, fever, abdominal pain and anaemia appeared. Leukocytosis, increased gamma GT, and globulin and slight albuminemia were found in our case, other earlier study followed increased alkali phosphatase and or elevated bilirubin but it was not found in our case. All of the routines of blood tests not specifically help to diagnose LA. However, they can suggest abnormalities in the liver, lead to targeted imaging studies.

LA may present as right side pulmonary infiltrate with pleural effusion by chest $\mathrm{x}$-ray. Abdominal $\mathrm{x}$-ray rarely used, may show air-fluid level or portal venous gas formation in adult. Ultrasound and Computed Tomography (CT) are common imaging diagnostic method with $96-100 \%$ sensitivity. It may show commonly hypoechoic than hyperechoic lesion compared to normal liver parenchyma. CT imaging with contrast-enhanced show rim enhancement in the abscess wall. Contrastenhanced ultrasound (CEUS) also have good sensitivity (86.6\% sensitivity, $99.8 \%$ specificity, $99.5 \%$ diagnostic accuracy) but rarely applied. ${ }^{11,12}$ CEUS is more sensitive in detecting even small abscesses anywhere in the liver. Our study found that the abdominal ultrasound found a mass in liver $4.5 \times$ $5.1 \mathrm{~cm}$ and CT scan with contrast examination had the same conclusion, an abscess $4.4 \times 4.3 \times 6.1 \mathrm{~cm}$ liver size.

Irrespective of any aetiology most of the liver abscess (approx. 2/3 $3^{\text {rd }}$ ) occur in the right lobe of liver and majority are solitary. Left lobe abscesses should be treated with caution as they are frequently associated with complications like rupture into peritoneum and pericardium and cause pericardial effusions. Left-sided liver abscesses require drainage far more often ( $85 \%$ cases) when compared to right sides lesions. A majority, pyogenic LA is usually solitary, located in the right lobe of the liver and is encased in the fibrous tissue. ${ }^{3,13,14}$ Our findings suggest that the hepatic abscesses were solitary and loculated in right lobe without rupture and the other complications.

When PLA is suspected, ALA must be excluded. Wide spectrum antibiotics should start immediately after microbiological specimen obtained. PLA found to resistance to ampicillin, antibiotics options for PLA: the third and fourth generation of cephalosporin, piperacillin/tazobactam and carbapenem remain effective. ${ }^{5,15}$ Initial antibiotics regimen recommended using third-generation cephalosporin and metronidazole or piperacillin/ tazobactam with advantage cover of enterococcal infection partly - duration of therapy determined by response to treatment. Resolution of fever, leukocytosis and abscess size by US imaging can describe a good response to treatment. Optimal duration of Intravenous and oral antibiotics remain unclear. Intravenous antibiotics 2-3 weeks and consecutive oral therapy for 1-2 weeks. ${ }^{15}$ In a study from Taiwan, Intravenous antibiotics consisted of weeks followed 1-2 month of oral therapy. ${ }^{16,17}$ This case report was treated by 2 combinations of antibiotics for A largeliver abscess day. Ceftriaxone $100 \mathrm{mg} / \mathrm{Kg} /$ day IV in 2 divided dose and Metronidazole $15 \mathrm{mg} / \mathrm{Kg}$ IV loading dose (once) continued to $7.5 \mathrm{mg} / \mathrm{Kg} / \mathrm{dose}$ 3 times in a day and continue with antibiotic oral Cefixime $5 \mathrm{mg} / \mathrm{kg} / \mathrm{kali}$ in 2 divided dose for 2 weeks. The results were good. Patients were discharged in good condition.

Not all LA required interventional therapy. Following criteria suggested for percutaneous drainage: PLA $>6 \mathrm{~cm}$ in size, impending perforation in US imaging, continued fever after 48-72 hour of adequate medical and aspiration treatment. ${ }^{5,16,25}$ ALA treatment is unique, a large abscess can resolved without drainage, even with one dose of metronidazole, its response to therapy within 72-96 hours, small abscess treated with drug alone, have same clinical improvement and mean hospital stay compared to aspiration group..$^{5,18,25}$ Our findings indicate that the abdominal ultrasound and CT scan with contrast examination had the same conclusion, an abscessed liver without perforation finding. The patient didn't have a fever after 48 hours of antibiotics used and septic marker progressively improved.

Anaemia that we found in our case was severe anaemia. With a high ferritin level and positive 
marker of inflammation and no blood loss in faeces or hemolytic sign, we think infection tend to be chronic. Chronic inflammation or disease may inhibit erythropoietin production and indirectly reduce iron absorption in the duodenum. ${ }^{17}$ So this case reduced serum iron not caused by low intake of iron.

Low socioeconomic status, anaemia and malnutrition are predisposing factors of LA. ${ }^{7,19,20}$ Incident of LA is vary from several studies, but it more often in children less than 5 years old. ${ }^{7,9}$ In a case report, our patient, lived in a small village but he was well-nourished and good appetite.

Anti amoebic serology is obtained in this case, but results are negative. We check it to exclude amoebic cause in our case. Several ways can provide serology of amoebic infection: stool, serum, pus or abscess antigen detection and serum antibodies detection. The sensitivity of serology can we see in the table $1 . .^{21,22}$

Diagnosis of LA from amoebic serology is considered as highly sensitive (>94\%) and highly specific $(>95 \%) .{ }^{18}$ The sensitivity of serology is better in the convalescent state $(>90 \%)$ than those obtained in acute illness. Serology conversion starts first 15 days of onset ${ }^{4,23}$ serologic negative value may be repeated 7-10 days with 2 or more serologic data or test of pus if aspiration or draining done by PCR examination. ${ }^{23}$ Serology may be still positive in serum antibody detection although its couple months or years may exclude amoebic LA if no kind of amoebic infection exist before. ${ }^{4}$

We conclude our case was pyogenic caused because the onset was more than 2 weeks and negative result of amoebic serum antibody. Although no pus or abscess collected to analyze. Clinical and laboratory improvement after antibiotics confirmed the diagnosis.

In other research showed one of the other factors associated with mortality were antibiotics alone without prompt drainage and one of the other factors associated with complications were the large size of the abscess. ${ }^{24,25}$ In the case report, the CT scan with contrast examination had found an abscess $4.4 \times 4.3 \times 6.1 \mathrm{~cm}$ liver size without rupture and the other complications. Patient treated by 2 combinations of antibiotics without prompt drainage and the result was good.

After clinical cure, patients show few symptoms and sonographic follow up demonstrates evidence of persistent hypoechoic lesion. The mean time for the disappearance of the sonographic abnormality is 6-9 months. ${ }^{1}$ The result of the previous study also found a similar finding whereas nine months after therapy the abdomen ultrasonographic was normal.

\section{CONCLUSION}

We report a case with liver abscess, physical examination and USG/CT-scan revealed the abscess was not more than $6 \mathrm{~cm}$ in size, and no sign of perforation was found. After 2 days of antibiotic therapy, the evaluation showed this patient could be treated without drainage or surgical procedure. The patient showed improvement in clinical and laboratory test after 10 days of intravenous antibiotics, and followed by 2 weeks of oral antibiotic. Long term follow up of this patient with ultrasonographic was normal.

\section{CONFLICT OF INTEREST}

There is no competing interest regarding the manuscript

\section{FUNDING}

None

\section{AUTHOR CONTRIBUTION}

All of the authors are responsible for the study from the conceptual framework, preparation of patient, data gathering, until reporting the outcome, in this case, report comprehensively.

\section{REFERENCES}

1. Dutta A, Bandyopadhyay S. Management of liver abscess. Medicine. 2012;22:469-75.

2. Sharma MP, Kumar A. Liver abscess in children. Indian Journal of Pediatrics. 2006;73(9):813-7.

3. Mishra K, Basu S, Roychoudhury S, Kumar P. Liver abscess in children: an overview. World J Pediatr. 2010;6(3):210-6.

4. Bisanto J, Firman K. Abses Hati pada Anak. Sari Pediatri. 2016;7(1):50-6

5. Lübbert C, Wiegand J, Karlas T. Therapy of liver abscesses. Viszeralmedizin. 2014;30(5):334-41.

6. Liu Y, Wang JY, Jiang W. An Increasing Prominent Disease of Klebsiella pneumoniae Liver Abscess: Etiology, Diagnosis, And Treatment. Gastroenterol Res Pract. 2013;2013:258514.

7. Simeunovic E, Arnold M, Sidler D, Moore SW. Liver abscess in neonates. Pediatr Surg Int. 2009;25(2):153-6.

8. Waghmare M, Shah H, Tiwari C, Khedkar K, Gandhi S. Management of Liver Abscess in Children: Our Experience. Euroasian J Hepatogastroenterol. 2017;7(1):23-26.

9. Salahi R, Dehghani SM, Salahi H, Bahador A, Abbasy HR, Salahi F. Liver abscess in children: a 10-year single centre experience. Saudi J Gastroenterol. 2011;17(3):199-202.

10. Lin AC, Yeh DY, Hsu YH, Wu CC, Chang H, Jang TN, et al. Diagnosis of pyogenic liver abscess by abdominal ultrasonography in the emergency department. Emerg Med J. 2009;26(4):273-5.

11. Popescu A, Moga T, Sporea I, Sandulescu L, Sirli R, Danila $\mathrm{M}$, et al. Contrast-Enhanced Ultrasound in the Diagnostic of Liver Abscesses. A Prospective Multicenter Experience. Ultrasound in Medicine and Biology. 2017;43(Suppl_1):S51. 
12. Bamberger DM. Outcome of medical treatment of bacterial abscesses without therapeutic drainage: review of cases reported in the literature. Clin Infect Dis. 1996;23(3):592-603.

13. Heneghan HM, Healy NA, Martin ST, Ryan RS, Nolan N, Traynor O, et al. Modern management of pyogenic hepatic abscess: a case series and review of the literature. BMC Res Notes. 2011;4(1):80.

14. Rahimian J, Wilson T, Oram V, Holzman RS. Pyogenic liver abscess: recent trends in etiology and mortality. Clin Infectious Dis. 2004;39(11):1654-9.

15. Liu Y, Wang JY, Jiang W. An increasing prominent disease of Klebsiella pneumoniae liver abscess: etiology, diagnosis, and treatment. Gastroenterol Res Pract. 2013; 2013:258514.

16. Stanley SL Jr. Amoebiasis. Lancet. 2003;361(9362):1025-34.

17. Weiss G, Goodnough LT. Anemia of chronic disease. N Eng J Med. 2005;352(10):1011-23.

18. Chaubey D, Pandey A, Kumar P, Gupta A, Rawat J, Wakhlu A, et al. Liver abscess in children: challenges in management. International Surgery Journal. 2016;4(1):107-10.

19. Ba ID, Ba A, Faye PM, Diouf FN, Sagna A, Thiongane A, et al. Particularities of liver abscesses in children in Senegal: Description of a series of 26 cases. Arch Pediatr. 2016;23(5):491-6.

20. Sánchez-Aguilar M, Moran-Mendoza O, HerreraHernandez MF, Hernández-Sierra JF, Mandeville PB, Tapia-Perez JH, et al. Prognostic indications of the failure to treat amoebic liver abscesses. Pathog Glob Health. 2012;106(4):232-7.
21. Tanyuksel M, Tachibana H, Petri WA. Amebiasis, an emerging disease. In: Emerging Infections American Society of Microbiology. 2001;5:197-212.

22. Tanyuksel M, Petri WA Jr. Laboratory diagnosis of amebiasis. Clin Microbiol Rev. 2003;16(4):713-29.

23. Otto MP, Gérôme P, Rapp C, Pavic M, Vitry T, Crevon L, et al. False Negative Serologies in amebic liver abscess: report of two cases. J Travel Med. 2013;20(2):131-3.

24. Alexopoulou A, Dimopoulou H, Soultati A, Panetsos G, Dourakis SP. Factor related to complications and mortality in pyogenic liver abscesses. Annals of Gastroenterology. 2010;23(4):296-301.

25. Bari S, Sheikh KA, Malik AA, Wani RA, Naqash SH.. percutaneous aspiration versus open drainage of liver abscess in children. Pediatr Surg Int. 2007;23(1):69-74.

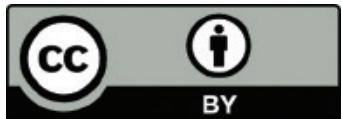

This work is licensed under a Creative Commons Attribution 